\title{
ATAQUE AOS ESTADOS UNIDOS: ALGUMAS IMPLICAÇÕES NO DIREITO INTERNACIONAL
}

\author{
Alkemi Maria Borcezzi*
}

SUMÁRIO: 1. Introdução. 2. O Ataque sob o ângulo de uma possível III Guerra Mundial. 2.1. O novo terrorismo e o direito intetnacional. 3. O principal suspeito e o envolvimento de um Estado. 3.1. A possibilidade de extradição. 4. Conclusião. 5.Bibliografia.

SUMMARY: 1. Introduction. 2. The Attack: a Possible III World War. 2.1. The New Terrorism and the InternationaI Right. 3. The Main Suspicion and the Envolvement of a State 3.1. The Possibility of Extradition. 4. Conciusion. 5.Bibliografia.

SUMARIO: 1. Introducción. 2. El Ataque: una Posible III Guerra del Mundo. 2.1. El Nuevo Terrorismo y el Derecho Internacional. 3. La Sospecha Principal y el Envolvimeinto de un Estado. 3.1. La Posibilidad de la Extradición. 4. Conclusión. 5. Bibliografia

RESUMO: Baseado em um caso real, o ataque contra os Estados Unidos, foi desenvolvida una análise considerando o direito internacional, focalizando o problema que a comunidade internacional irá enfrentar e o que tem sido feito para solucionar o problema. Primeiro, há algumas considerações sobre a guer$r a$ os acordos internacionais que poderão ser invocados neste caso, o que é terrorismo e se há alguma resposta que poderá ser cncontrada no direito internacional para combater esse tipo de situação. Finalmente, o estudo aponta em quais casos poderá ser invocada a extradição para conduir se nesta situação há alguma possibilidade de usá-la. Após essas considerações, na conclusão está sendo discutido sobre os instrumentos que o direito internacional oferece na atualidade e se estes são suficientes para controlar esse tipo de violència.

\footnotetext{
"Mestre en Dirito Negocial pela Univeridade Estadual de Londrina. Proto de Direto Intemacional ia Univeridade Paranaense - UNIPAR. Prof da Universidade Estadual de Londina - UEL
} 
ABSTRACT: Based in the attack against United States, it was developed an analysis considering the international law, focusing some problens that international community will face and what has been done to solve them. Firstly, there are some considerations about war and international agreements that could be invocated in this case, about what is terrorism and if there is any answer in the international law to combat this situation. Finally, the study points out in which cases could be invocate the extradition to conclude if in this situation there is some possibility to use it. After all this considerations, in the conclusion had been discussed about the instruments that the international law offer in actuality and if this ones is enough to control this kind of violence.

RESUMEN: Basado en un caso verdadero, el ataque contra los Estados Unidos, fue desarrollado un análisis que considera el derecho internacional, enfocando el problema a que la comunidad intemacional hará frente y qué ha hecho para solucionar el problema. Primeramente, hay algunas consideraciones sobre la guerra, los acuerdos internacionales que podnian ser invocadas en este caso, cuál es terrorismo y si hay una cierta respuesta que podria ser hallazgo en el derecho internacional para combatir esta clase de situación. Finalmente, el estudio precisa en qué casos podria ser invocada la extradición para conduir si en esta situación hay una cierta posibilidad para utilizarla. Después de todo este las consideraciones, en la conclusión habian sido discutidas sobre los instrumentos que la oferta internacional del derecho en actualidad y si éstos son bastantes para controlar esta clase de violencia.

PALAVRASCHAVES: Direito Internacional. Guerra. Terrorismo. Extradição.

KEY-WORDS: International law. War. Terrorism. Extradition.

PALABRASLLAVES: Derecho internacional. Guerra. Terrotismo. Extradicción.

\section{Introdução}

A agressão, sem precedentes, a que foi submetido o povo Americano no recente 11 de setembro de 2001 , por certo marcará o início desse século. Tem-se plena consciência que, estando a menos de uma semana desse lamentável episódio ${ }^{1}$, não há como ser feita qualquer avaliação profunda de seu impacto no direito internacional. No entanto, a intenção é 
modesta: busca-se apenas observar o que está acontecendo pelo ângulo do direito internacional, principalmente, o direito internacional público.

Exatamente 28 anos após a construção do World Trade Center, em Nova Iorque, principal símbolo do capitalismo ocidental, um Bocing 767, da American Airlines é seqüestrado e arremessado de encontro a uma das torres do prédio. Menos de quinze minutos depois, outro avião Boeing 767, também carregado de civis, choca-se contra a outra torre do edificio. Quarenta minutos depois, outro Boeing seqüestrado é lançado contra o Pentágono, a três quilômetros da Casa Branca, em Washington.

A série de barbáries cometida contra essa nação colocou por terra dois de seus principais símbolos: as torres do World Trade Center, representando a supremacia econômica de uma superpotência, e um dos prédios do Pentágono, sede do poder militar desse império. Mas isso não foi tudo, pois o fato abalou os alicerces do mundo em inúmeros aspectos.

E certo que esses atos produzem efeitos em vários segmentos, como os políticos, cconômicos, sociais, ou seja, tudo hoje no mundo está visivelmente comprometido em virtude dessa injustificável violência.

Mas, especificamente quanto ao direito internacional, como se deve analisar suas implicações? Essa é a proposta.

Fala-se a todo o instante sobre a possibilidade de uma terceira guerra mundial. Sem enveredar para o campo das previsões e análise de probabilidade, o que será verificado é o que caracteriza a guerra e, com base nos elementos que até agora se dispõe, como poderão os Estados Unidos reagir.

Outro enfoque será a questão do terrorismo frente ao Direito Internacional Público. O que altera?

Esse episódio ainda está envolvendo institutos de direito internacional privado, como é o caso da extradição. Essa questão deverá ser revista em função dos problemas que as nações, de modo geral, vem sofrendo em conseqüência desse novo terrorismo?

Um dos principais acusados de liderar esse ataque é Osama bin Laden, que atualmente se esconde no Afeganistão, país liderado pelo regime Taleban, cujo governo somente é reconhecido pelos Emirados Árabes, Arábia Saudita e Paquistão. Esse fato traz alguma consequêencia jurídica?

Por fim, fala-se em uma Nova Ordem Mundial. O que leva a tal afirmativa? Essa nova ordem de que se fala decorre dos aspectos já levantados e será enfocada por ocasião da conclusão. 
Essas são algumas das implicações do direito internacional a serem analisadas a luz da tragédia ocorrida, cuja finalidade do estudo é apenas extrair alguns questionamentos juridicas, possibilitando-se uma visão crítica, preparando-se, assim, para as eventuais mudanças que venham a ocorrer.

\section{O Ataque sob o ângulo de uma possível III Guerra Mundial}

O principal temor da comunidade internacional está centrado na possibilidade desse evento desencadear uma III Guerra Mundial. Alguns noticiários chegaram a comparar o episódio ao ataque feito a base naval de Pearl Harbor, pelo Japão, em 07 de dezembro de 1941. Foi um ataque surpresa, sem qualquer prévia declaração de guerra por parte do Japão. Somente o fator surpresa pode levar ao comparativo. Nada mais.

No caso, não se está diante de um ataque feito por um Estado inimigo. Trata-se, ainda, de um inimigo sem face.

Os constantes conflitos entre os povos fizeram desenvolver o "Direito da Guerra" - Jus in bello - referindo-se esse àquele conjunto de normas, a princípio costumeiras, passando posteriormente a normas convencionais, regulamentando questốes relacionadas ao uso da força, buscando the dar ares mais justos e, até a primeira metade do século passado, a guerra, justa ou não, foi juridicamente aceita. Atualmente, a tolerância com relação a guerra limita-se a hipótese de uma defesa real contra uma agressão armada e, ainda, no caso de luta pela autodeterminação de um povo contra a dominação colonial ${ }^{2}$.

Os efeitos nefastos provocados pela II Guerra Mundial, fizeram com que os Estados buscassem inseri-la como um ilícito internacional. Mas, por evidente, cientes da impossibilidade de varrer da cena internacional a possibilidade de uma eventual eclosão de um conflito armado, foram firmadas em Genebra, quatro convenções versando sobre a proteção dos feridos e enfermos, na guerra terrestres; feridos, enfermos e náufragos, na guerra naval; o tratamento devido aos prisioneiros de guerra e a proteção aos civis em tempo de guerra ${ }^{3}$.

Desse relato, observa-se que a Comunidade internacional, a fim de evi- 
tar a selvageria, criou regras a serem seguidas, caso o ilícito ocorresse. Uma das regras básicas, em caso de guerra: não se agride a população civil. E, outra regra basilar também, o inimigo se apresenta e declara a guerra.

No entanto, não se está diante de uma Guerra iniciada por um Estado contra outro. O que se tem, é um inimigo oculto, covarde, extremamente sanguinário, que ataca de surpresa e não mede esforços para agredir os mais frágeis: a população civil.

\subsection{O novo terrorismo e o direito internacional}

O terrorismo clássico, desenvolvido nos anos 70 e 80 , caracterizava-se pela ação de grupos conhecidos, cujas propostas politicas eram bem definidas. Via de regra assumia seus atos. Além disso, os países que o patrocinavam não costumavam esconder o fato da comunidade internacional. Os principais exemplos disso eram o IRA - exercito de libertação da Irlanda do Norte - , a Frente Popular para Libertação da Palestina, dentre outras. Atualmente ainda há exemplos desse velho terrorismo, como é o caso do ETA, cujo objetivo declarado é obter da Espanha a independência da província basca, e facçóes radicais do IRA, na Irlanda do Nortet.

O que ocorreu no último dia 11.09.01, nos Estados Unidos, é o que os especialistas em relações internacionais têm nominado de "novo terrorismo". Nesse caso, busca-se atingir um grande número de vítimas fatais, o ataque suicida é feito a alvos simbólicos e existe demora em assumir a autoria. O novo terrorismo se esconde atrás do sofisma da religião, mas na verdade o que buscam é o poder seja a que preço for e, de preferência, com muito sangue.

A comunidade internacional já tem se movimentado no intuito de tentar minimizar essa agressão surgida no século passado que, infelizmente, nos acompanha com força total nesse século.

A União Européia, visando coibir essa prática, introduziu no Tratado de Maastricht, através do artigo 29, do Tratado de Amsterdă, o expresso combate ao terrorismo, autorizando os Estados-membros a adotarem posições comuns para combate a esse fenômeno. Foi criado, ainda, o Serviço Europeu de Polícia (Europol), cuja convenção entrou em vigor em 01/10/ 98 , bem como a cooperação policial em matéria de terrorismo5 ${ }^{5}$. 
Frente a esses problemas, as ações, sem dúvida, devem ser conjuntas. É inimaginável pensar na possibilidade de combater um inimigo dessa envergadura sem a colaboração dos demais países. É justamente aí que os problemas começam.

Se houve um periodo que efetivamente marcou o direito internacional, sem qualquer receio pode-se afirmar ter sido o fim da Segunda Guerra Mundial. As principais medidas, alianças, incremento das Organizações Internacionais ocorreram, efetivamente, após o término da Segunda Guerra Mundial.

Naquele momento histórico os países tinham apenas uma certeza: a Segunda Guerra somente ocorreu por ausência diplomacia internacional realmente eficaz, considerando que a organização encarregada de tal mister - Liga das Nações - havia fracassado em seus propósitos.

Os Estados Unidos, que no período da primeira Guerra Mundial, permaneceu no isolacionismo, após a segunda guerra rompe com Moscou e se convence da necessidade da formação de organismos regionais de defesa'. Esse fator deu novo impulso as relações internacionais, considerando o forte peso daquele país, surgindo aí vários órgãos de cooperação militar e, dentre eles, destaque-se dois, de interesse para o presente estudo: TIAR - Tratado Inter-americano de Assistência Recíproca, que reúne os países da América e aTAN - Organização do Tratado do Atlântico Norte, congregando Estados Unidos e Europa Ocidental, contando hoje com participação de 19 Estados?

Esses acordos foram firmados em consonância com os principios norteadores, contidos na Carta das Naçôes Unidas, sendo tratados de natureza militar, de alcance militar, e estão sendo invocados nesse momento histórico, como meio para alcançar o apoio dos países com relação as medidas a serem tomadas para o combate ao terrorismo, em especial, para o caso que está sob análise.

Buscando apoiar a nação atingida, em momento tão delicado, o Brasil invocou o Tratado Interamericano de Assistência Recíproca (TIAR) adotado em 1947, para convocar os 34 países do Continente americano, a deliberar em bloco sobre uma postura ante os atentados ${ }^{\S}$.

Mencionado tratado, cuja vigência teve início no Brasil em 25/03/48,

EUROPEAN UNION. Consultado na internet em 16 de setembro de 2001. http:/ europa.eu.int/ scadplus/leg/pt/cig/g4000l htm

"SEITENFUS, Ricardo. O Manual das Otganizaçoes Intemacionais. Porto Alegre: Livraria do Advogado, 1997, p.234. 
do qual os Estados Unidos também faz parte, reflete o interesse suscitado no item 1, ou seja, de deixar positivado ser a guerra um ilícito, o que é feito através do artigo 10 ?

Mas em ocorrendo um ataque contra um dos seus Estados-partes, estipulam em seu artigo 3:

1. As Altas Partes Contratantes concordam em que um ataque armado, por parte de qualquer Estado, contra um Estado Americano, será considerado como um ataque contra todos os Estados Americanos, e, em conseqüência, cada uma das ditas Partes Contratantes, se compromete a ajudar a fazer frente ao ataque, no exercício do direito imanente de legítima defesa individual ou coletiva que é reconhecido pelo Artigo 51 da Carta das Nações Unidas.

Ou seja, é uma proposta de ajuda recíproca. Mesmo não estando em guerra, frente a um ataque, poderão os Estados-partes deliberar ações conjuntas, admitindo, se for o caso, colaboração nas investigações, auxílio armado, enfim, o que se fizer necessário.

As relações no âmbito do direito internacional se desenvolvem horizontalmente, através de relações coordenadas. $O$ tratado em questão propicia uma saída jurídica visando uma deliberação conjunta com relação a medida a ser aplicada para combate ao terrorismo sofrido pelos Estados Unidos. Não é declaração de guerra, não significa envio de tropas, mesmo porquê o inimigo, por enquanto, não é um Estado, há apenas suposições com relação a determinado grupo terrorista.

No mesmo sentido da saída encontrada pelo Brasil, foi a declaração da OTAN. O artigo $5^{\text {a }}$, do Tratado do Atlântico Norte, de 04/04/49, faz com que um ataque armado contra um dos países da Europa ou da América do Norte, seja considerado como um ataque contra todos e, conseqüentemente, cada um deles, no exercício de seus direitos individuais ou coletivos, poderão atacar sob o fundamento da legítima defesa, tanto individualmente como em conjunto com os outros Estados Partes, adotando-se as medidas necessárias para tanto ${ }^{10}$.

Note-se que o princípio é o mesmo daquele contido no artigo $3^{\underline{a}}$,do TIAR. A guerra continua sendo considerada um ilícito, a possibilidade de sua adoção é somente no caso de legítima defesa e, a proposta de auxílio

\footnotetext{
"In: http:/wwwnatoin/t). Páses que compōe a OTAN: Bélgica, Canadá, República Tcheca, Dinanar-

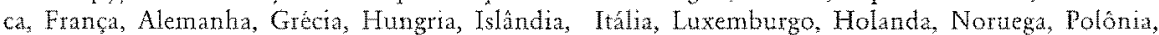
Portugal, Espanha, Turquia, Reino Unido, Estados Unidos.

"Folha de Londrina - Folha Paraní. Taleban Ameaça paíse vizinhos, Londrina, 16.0901, caderno: "Mundo", p.13 "As altas Partes Contratantes condenam formalmente a gucra e se obrigam, na suas relaçôes internacionas, a não recorrer a ameaça nem ao uso da força, de qualquer forma incompativel com as disposiçóes da Carta das Nações Unidas on do presente Tratado.
} 
recíproco dependerá, sempre, de consultas e decisões junto as Organizações Internacionais dos quais os paises fazem parte.

Outra notícia veiculada, que tem causado bastante polêmica, é a aprovação pelo Senado Americano, por unanimidade de votos, com relação autorização do uso, pelos Estados Unidos, de forças Armadas contra aqueles responsáveis pelos recentes ataques lançados contra o país ${ }^{1 !}$.

A autorização também não significa declaração de guerra e muito menos carta branca para agir, invadindo qualquer Estado. Mas a utilização do uso das forças armadas caso constate-se o responsável pelos atentados. É isso o que se tem até o momento.

Essa realidade deu mostra do despreparo mundial para enfrentar o terrorismo. No mínimo, aponta para a necessidade de medidas urgentes, trabalho conjunto dos países, pois, se hoje a agressão foi contra os Estados Unidos, amanhã poderá ser contra qualquer outro país. Como bem ressaltou o especialista na matéria,Ian $O$. Lesser, em entrevista concedida à revista Veja, terrorismo é comparável ao crime.Podemos reduzir o índice de assaltos, mas não acabar de vez com eles ${ }^{12}$.

Considera-se o atentado como uma violência e uma agressão contra o mundo, não apenas contra um determinado país. Tanto que no incidente ocorrido, dezenas de brasileiros foram atingidos pois eram pessoas que trabalhavam no local ou lá estavam por alguma razão. Assim como havia brasileiros, havia pessoas de várias outras nacionalidades, afinal, estamos o tempo todo nos inter-relacionando. E, como já foi dito, se isso ocorreu no quintal do vizinho, amanhã poderá ocorrer no nosso.

Por isso, há premente necessidade da Comunidade Internacional estudar medidas mais eficazes possíveis para impedir tais açōes. Se não para combate-las em sua totalidade, ante a utopia da proposta, no mínimo para reduzi-la a padrões mínimos, protegendo-se, assim, a população civil.

O momento não é de guerra, mas de união na luta contra um inimigo comum: o terrorismo.

\footnotetext{
10 NORTH ATLANTIC TREATY ORGANISATION. Consultado na intemet em 16 de setembro de 2001. http://www nato.int/4t.

Art. 5: The Parties agree that an armed attack against one or more of them in Europe or North America shall be considered an attack against them all and consequently they agree that, if such an armed artack occurs, each of them, in exercise of the right of individual or collective self-defence recognised by Article 51 of the Charter of the United Nations, will assist the Party or Parties so attacked by taking forthwith, indiwidually and in concert with the ocher Parties, such action as it deems necessary, including the use of armed force, to restore and maintain the security of the North Adantic area.

Any such armed attack and all measures taken as a result thereof shall immediately be reported to the Security Council. Such measutes shall be terminated when the Security Council has taken the measures necessary to restore and maintain international peace and security (1).
} 


\section{O principal suspeito e o envolvimento de um estado}

Outra questão que merece apreciação sob o enfoque do direito internacional, é a suspeita que paira sob o líder terrorista Osama bin Laden. É bom mais uma vez frisar: está sendo utilizado o fato para discutir questões que envolvem o direito internacional. Poderia ser qualquer outro nome, mas veicula-se a possibilidade de que o ataque tenha sido perpetrado por essa pessoa.

Tal circunstância desencadeia uma série de questionamentos no âmbito do direito internacional: envolvimento dos países que o abrigam, possibilidade de invasão, como deve ser analisada a possibilidade de extradição, considerando sempre aquilo que existe de concreto, até o momento, com relação a esse instituto. $O$ nome suspeito traz a tona mais uma discussão: este líder estaria escondido em um país cujo governo não é reconhecido pela maioria dos países que compõe a comunidade internacional. Quais os reflexos disso?

Os aspectos fáticos, nesse caso, são necessários para a compreensão do caso.

Osama bin Laden, filho de Mohamed bin Laden, nascido na Arábia Saudita, desde 1979 atua como militante islâmico e participou do combate ao comunismo da União Soviética, juntando-se a um grupo que reunia Mulçumanos de diferentes procedências e fundamentalistas do Taleban bem como outras facções de defesa do país. Os rebeldes afegãos receberam o apoio dos Estados Unidos para enfrentar a superpotência comunista. Dez anos de luta, culminou com a retirada dos soviéticos, o que serviu de estímulo para a criação de grupos de fanáticos fundamentalistas em outras nações islâmicas.

Terminada a guerra Osama bin Laden volta ao seu país, Arábia Saudita, onde lidera um movimento de libertação da Arábia Saudita e Israel da influência ocidental. Pelo fato de tal movimento tê-lo colocado como opositor do regime saudita, Laden foi expulso de seu país e teve sua cidadania cassada. A princípio foi para o Sudão, tendo de lá sido banido em 1996, quando então foi acolhido pelo Afeganistão.

Tem-se, assim, um cidadão Saudita, acolhido no Afeganistão e sob o qual recai a grave acusação de ter participado dos atentados nos Estados Unidos.

"UNTTED STATES SENATE. Site consultado na internet em 16 de setembro de 2001.http/ www senategov/ legislative/vote1071/rote_00281.htmMeasure Title: A joint resolution to anthorize the use of Uated States Armed Forces against those responsible for the recent attacks launched against the United States ${ }^{12}$ LESSER, lan O.. O nowo terrorismo. Revista Vẹa, Sto Paulo: Abril, 19.09.2001, ano 34, na 37, ed.1718, p.14. Entrewista, p.15. 
Sob esse enfoque as questões agora passam a ser examinadas.

\subsection{A possibilidade de extradição}

Veicula nos noticiários a afirmação de que os Estados Unidos iria solicitar a extradição de Osama bin Laden, que atualmente se esconde no Afeganistão. Esse país, se encontra sob o governo Taleban, liderado por Mulá Mohammad Omar, e ele foi taxativo ao afirmar que a possibilidade de extradição somente iria ser examinada se os Estados Unidos fornecessem provas sólidas e convincentes de seu envolvimento com o terrorismo ${ }^{13}$.

Embora a extradição seja um instituto de raízes bastante antigas, a sua utilização e aplicabilidade persistem, com bastante intensidade, nos dias atuais.

A maioria dos autores faz uso da clássica definição trazida por Hildebrando Accioly de que extradição é o ato pelo qual um Estado entrega um indivíduo acusado de fato delituoso ou já condenado como criminoso, à justiça de outro Estado, competente para julgá-lo e puni-lo ${ }^{14}$.

Trata-se de um instituto de cooperação internacional em matéria penal cuja indiscutível utilidade alia dois valores aparentemente antagônicos: de um lado viabiliza a intensificação da luta contra o crime, possibilitando, através de atos de cooperação internacional, seja o extraditando submetido a execução da pena já imposta ou que responda, perante o órgão competente do Estado requerente, quanto a acusação que lhe é imputada. A par disso, considerando que a extradição pauta-se pelo princípio do devido processo legal, assegurando, portanto, a ampla defesa ao extraditando, é certo que o outro valor que dele emerge é o respeito aos direitos fundamentais do homem. Portanto, esses interesses, embora díspares, é o que dá equilíbrio e fixa o limite da cooperação internacional.

Analisando-se o instituto tem-se, portanto, como requisitos para a extradição, a necessidade da existência de um acordo de cooperação internacional em matéria penal entre os Estados e a existência de um processo criminal contra a pessoa acusada, seja em trâmite ou concluído. No entanto, a história registra casos de extradição onde o requisito relativo ao acordo de cooperação em matéria penal não existia. No Brasil, tem-se como exemplo o pedido de extradição feito à Inglaterra para captura do já falecido criminoso Paulo César Farias. 
O extraditando foi localizado na Inglaterra, país com o qual o Brasil não possuía qualquer tratado relacionado com extradição e nem havia promessa de reciprocidade. No entanto, a diplomacia brasilcira obteve junto ao governo britânico a excepcional figura da extradição ad hoc, com o específico objetivo de atender aquele caso. Mas, como é sabido, após a assinatura da mencionada extradição ad hoc, decretando a prisão preventiva de Paulo César Farias, essa não se consumou em consequência de sua fuga. Posteriormente foi localizado na Tailândia, portando passaporte e nome falsos, ocasionando a sua sumária deportação, colocando-o a disposição das autoridades brasileiras.

Se o caso Paulo César Farias marcou o amadurecimento da extradição ativa no nosso país, sem dúvida, o marco da extradição passiva deve ser concedido ao caso de Franz Paul Stangl ${ }^{15}$, julgado em 7 de junho de 1967, perante o Supremo Tribunal Federal, que contou com a participação de renomados juristas dentre os quais destaca-se o Ministro Aliomar Baleeiro, tendo como Ministro relator Victor Nunes Leal e, na qualidade de Procurador Geral da República, o Prof. Haroldo Teixeira Valladão.

A solicitação de extradição decorria de ser o austríaco Franz Paul Stangl acusado de co-autoria em crimes de homicídio, praticados em massa, por ocasião da guerra, em campos de extermínio em Hartheim, na Austria, Sobibór e Treblinka. Três paises fizeram a solicitação: Áustria, Polônia e Alemanha.

O julgamento envolveu a análise de questões de alta indagação no direito extradicional, como a análise do princípio da reciprocidade, a nacionalidade do extraditando, o problema do genocídio, a questão da exceção de crime político, a prescrição, a comutação de pena, a ordem de preferencia para entrega do extraditando. Embora mencionado julgamento tenha sido proferido a luz do decreto-lei 394/38, aplicando-se, ainda, a constituição federal de 1967 , a doutrina invocada é extremamente valiosa.

Outra consagrada classificação é a que diferencia a extradição instrutória da extradição executória. Na instrutória, a pessoa sujeita a extradição está apenas sendo acusado da prática de um fato delituoso

13 Folha de Londrina - Folha do Paraná. Afeganistão diz que só entrega Bin Laden comprova concreta. 15.09 .01 , cadeno 1, p.8.

:4 Manual de Dircito Internacional Público. $12 \mathrm{a}$ ed. Säo Paulo: Saraiva. 1996, p.347 
mas ainda não há decisão acerca do caso. Já na executória, o extraditando já foi processado e condenado criminalmente, devendo ser devolvido ao Estado de origem para o cumprimento da pena.

Essa distinção é importante para determinar quais os requisitos de admissibilidade da pretensão extradicional, ou seja, saber se o extraditando é réu ou condenado tem estreita correlação com a prova produzida no processo originário.

Exemplificando, no caso Franz Paul Stangl, o extraditando ainda não havia sido condenado pelos crimes que estava sendo acusado. Foram considerados como suficientes a comprovação da materialidade dos crimes e apresentação de indícios de participação do extraditando na atividade criminosa.

Por fim, tem-se a distinção entre extradição de fato e extradição de direito.

A extradição de direito se conduz em conformidade com o ordenamento jurídico interno ou internacional. Enfim, é o que desenvolve em conformidade com o devido processo extradicional.

Na extradição de fato, há a entrega sumária do indivíduo por parte do Estado a outro, sem qualquer procedimento jurídico. Gilda Russomano exemplifica:

$O$ Rio Grande do Sul oferece um exemplo vivo e ainda atual de extradição de fato. Pela circunstância de que, não raro, as fronteiras do Brasil com as nações do rio da Prata são linhas imaginárias e, até mesmo, ruas comuns a duas cidades sob bandeiras diferentes - reiteradas vezes, a entrega dos delinquentes se faz, sem quaisquer formalismos, por via puramente policial, mediante entendimento entre as autoridades locais." 16

A extradição de fato não deve ser confundida com a abdução internacional onde ocorre a ilegal apreensão do perseguido em território estrangeiro, sem qualquer formalidade, afrontando não só a soberania do outro Estado como também os direitos individuais daquele que sofre a apreensão.

Essas são, em linhas bem gerais, alguns dos aspectos teóricos que envolvem o instituto. No caso em estudo, o que se tem é um cidadão que vive refugiado em um país, sem que sobre ele recaia qualquer acusa- 
ção formal e sem que exista um acordo de reciprocidade entre os países, o que, como se viu, não seria o elemento mais complicado dessa questão, pois a história registra precedentes. A diplomacia, nesses tipos de casos, sempre é o melhor caminho. No entanto, as relações entre o Afeganistão e Estados Unidos, sob o comando de um grupo cujo governo não é reconhecido, não se pode dizer que seja das mais amistosas. Ademais, não reconhecimento de governo afasta qualquer possibilidade de relações diplomáticas.

Pelo que se tem, até o momento, em termos de extradição, pode-se afirmar ser legal qualquer recusa por parte desse país, com relação a extradição. Evidentemente, se houver comprovação, poderá a recusa ser considerada injusta, mas nunca de ilegal.

\section{Conclusão}

Noticiou-se que o primeiro ministro Tony Blair conclamou a comunidade internacional a iniciar uma intensa e conseqüente discussão para combater o terror, através da revisão de leis de extradição, da repressão a meios de financiamentos de grupos paramilitares e do combate ao crime organizado internacional ${ }^{17}$.

O grande problema que se enfrenta é o fato de o direito internacional não dispor de ferramentas eficazes para o combate ao terrorismo. Sempre que o direito não atende a sua finalidade precípua, ou seja, manter a paz social, os riscos de conflitos aumentam. Se na seara interna, uma situação como essa pode gerar um caos, transponha isso para o âmbito internacional., onde o resultado pode ser uma desastrosa e sangrenta guerra. É nesse clima de incerteza que o mundo se encontra. Ainda não se sabe ao certo quem são os culpados pela violência desmedida imposta a um país. Mas, já se tem dimensão do problema a ser enfrentado pelos Estados Unidos.

Supondo ser Osama bin Laden o agressor, o qual goza de profundo prestígio junto ao grupo de radicais do Taleban e atuais dominadores do Afeganistão, dificilmente os Estados Unidos conseguirá obter a extradição. Aliás, năo é de hoje que o país tenta a extradição, pois outros ataque 4 s, evidentemente que não tão violentos como esse, já ocorreram e o pedido

\footnotetext{
as a soUd Artur de Brito. As Novas Tendências do Direito Extradicional. Rio de Janeiro:
} Renovar, 1998, p.33 
foi feito várias vezes, mas a resposta sempre foi negativa. Nesse caso, que medida tomar? É possível admitir uma retaliação a um país pela atitude de um grupo que os domina pela força e nem como governantes são reconhecidos?

O inimigo não é aquele país de miseráveis, massacrados por décadas de guerra que sacrificam sua população, ultrajados em seus direitos humanos por um grupo de fanáticos que detém o poder. A Care USA, agência humanitária baseada em Atlanta, que vem operando no Afeganistão a aproximadamente trinta anos, declarou que muito embora o movimento Taleban ofereça refúgio ao terrorista suspeito, a maioria dos afegãos não subscrevem sua "guerra santa". As declarações de Peter Bell, presidente da Care, que visitou o Afeganistão, em junho, foram:

"É importante distinguir entre os governantes Talebans, de um lado, e a vasta maioria do povo afegão, do outro. A vida, nos últimos anos, ficou ainda mais difícil por causa da seca. Ao menos nas comunidades que visitei, senti uma desilusão por parte do povo em relação aos éditos duros do Taleban e às constantes violações de direitos humanos":18.

Sem dúvida, a comunidade internacional será conclamada a buscar saidas para o atual problema. Não para proteger o país A, B ou C. As medidas, na realidade, estarão sendo tomadas como forma de autoproteção. Para tanto, será necessário o esforço conjunto, no intuito de combater não só a causa, como os efeitos. Ou seja, sustenta-se ser a causa desse desenfreado crescimento do terrorismo internacional a insatisfação com a globalização, com a crescente desigualdade econômica entre os países. É certo que essas razões nunca poderão ser invocadas por grupos radicais como de Osama bin Laden, já que suas agressões se justificam apenas pelo objetivo de impor sua fanática versão do Islã ao mundo. Mas, o terrorismo vem também de outros lados, daí a necessidade de se analisar e combater as causas que levam a esse constante conflito, bem como buscar meios jurídicos para combater de forma eficaz a violência que o terrorismo causa.

Tudo isso, por certo, conduzirá a uma nova ordem jurídica internacional.

Poder-se-ia chamar esse trabalho apenas de um exercício teórico feito em cima de um caso prático. Não foi, e não é a intenção, apresentar uma

\footnotetext{
${ }^{17}$ Folha de Londrina - Folha Paraná. Afeganistào diz que só entrega Bin Laden com prova concreta., caderno: "Mundo", 15.09.01, p.08
} 
solução ou tecer hipóteses, com relação ao ocorrido. Chama-se a atenção apenas para o aspecto de como as relaçôes internacionais estão sendo desenvolvidas.

Muito embora o momento seja de comoção social, há uma ordem jurídica internacional que vem sendo trabalhada e muito provavelmente venha a ser modificada. Mas, o fato é que a comunidade internacional respeita e trabalha com aquilo que essa ordem determina. Nem mesmo uma superpotência, como é o caso do país agredido, irá abandonar por completo essas regras, respondendo com a fúria, pois necessita do apoio dessa comunidade. Comunidade essa que aprendeu a trabalhar de formar coordenada, sem um órgão superior a lhe impor as regras e por certo não irá apoiar e se aliar àquele que responde com excesso a uma agressão.

E assim trabalha a comunidade internacional. Pode não ser perfeita, mas possui suas regras. Por vezes modifica, adapta às suas novas realidades, mas, enfim, existe uma ordem jurídica internacional e é a luz dessa ordem que os fatos ocorridos devem ser analisados.

\section{BIBLIOGRAFIA}

BASU, Moni. Maioria no Afeganistão não apóia Bin Laden uol-mídia global - cox new service - new york times. Trad.: Deborah Weinberg. Site consultado na internet em 17.09.01. http://www.uol.com.br/times/nycox/ ult584u13.htm.

BOSON, Gerson de Britto Mello. Direito Internacional Público - O Estado em Direito das Gentes. 3o ed., Belo Horizonte: Del Rey, 2000.

CUNHA, J. da Silva. Direito Internacional Público - Introdução e Fontes. $5^{\circ}$ ed.,Coimbra: Almedina, 1993.

EUROPEAN UNION. Consultado na internet em 16 de setembro de 2001. http:/europa.eu.int/scadplus/leg/pt/cig/g4000l.htm

Folha de Londrina - Folha do Paraná. Afeganistão diz que só entrega Bin Laden comprova concreta. 15.09.01, caderno 1, p.8.

Folha de Londrina - Folha Paraná. Taleban Ameaça países vizinhos. Londrina, 16.09.01, caderno: "Mundo", p.13

Hildebrando Accioly Manual de Direito Internacional Público. 12a ed. São Paulo: Saraiva. 1996.

LESSER, Ian O.. O novo terrorismo. Revista Veja. São Paulo: Abril, 19.09.2001, ano 34, n 37, ed.1718, p.14.Entrevista.

MELLO, Celso D. de Albuquerque. Curso de Direito Internacional Público.

BASU, Moni. Maioria no Afeganistăo não apóia Bin Laden uol-midia global - cox new service - new york times. Trad.: Deborah Weinberg. Site consultado na internet em 17.09.01, http//www wolcom.br/ tines/nycox/ult584u13.hem. 
$12^{\circ}$ ed., vol.I e II, Rio de Janeiro: Renovar, 2000

NORTH ATLANTIC TREATY ORGANISATION. Consultado na internet em 16 de setembro de 2001. http://www.nato.int/\#.

REZEK, J. F. Direito Internacional Público - Curso Elementar. $8^{\circ} \mathrm{ed}$., revatual. São Paulo: Saraiva, 2000.

SEITENFUS, Ricardo. O Manual das Organizações Internacionais. Porto Alegre: Livraria do Advogado, 1997.

SOUZA, Artur de Brito. As Novas Tendências do Direito Extradicional. Rio de Janeiro: Renovar, 1998.

Supremo Tribunal Federal. Extradiçǒes - Julgamentos e Legislação. Brasília, 1976.

UNITED STATES SENATE. Site consultado na internet em 16 de setembro de 2001.http:/www.senate.gov/legislative/vote1071/vote_00281.htm. 